\title{
Profesionalne opasnosti i rizici u radu operacijskih sestara/tehničara Occupational Hazards and Risks in Work of Surgical Nurses and Technicians at surgical ward
}

\author{
Blaženka Kozina, Snježana Bastaja \\ Operacijski centar, Klinička bolnica Dubrava, Avenija Gojka Šuška 6, 10000 Zagreb, Hrvatska \\ Operating center, Clinical Hospital Dubrava, Avenija Gojka Šuška 6, 10000 Zagreb, Croatia
}

\begin{abstract}
Sažetak
Zdravstveni djelatnici u operacijskoj dvorani izloženi su raznim profesionalnim opasnostima poput bioloških, kemijskih, fizičkih i psihosocijalnih opasnosti koje mogu dovesti do ozbiljnih akutnih i dugoročnih štetnih zdravstvenih ishoda. Kod izvršavanja svojih radnih zadataka, operacijske sestre/tehničari susreću se $s$ različitim profesionalnim zdravstvenim problemima. Operacijska je dvorana prostor gdje djelatnici kirurškog tima djeluje u interakciji jedan s drugim te $s$ tehnološkim sredstvima. Operacijske sestre/tehničari značajno su osjetljivi na stresne čimbenike, izloženi su specifičnom radnom okruženju koje zahtijeva tehničku organizaciju i iskustvo, rukovanje s preciznim instrumentima, ovladavanje složenim tehnikama, uz to i zatvorena radna okolina - rad s istim osobama, rad bez duže interakcije s bolesnikom. Upravo zbog složenosti posla i odgovornosti, operacijske sestre /tehničari su izloženi stresnim situacijama koje su često previsokog stupnja i predugog trajanja što ih svrstava u rizičnu skupinu za nastanak stupnja sagorijevanja (engl. Burnout).
\end{abstract}

Ključne riječi: operacijske sestre • operacijska dvorana • profesionalne opasnosti • stres • sagorijevanje

Kratki naslov: Profesionalne opasnosti i rizici i operacijske sestre/tehničari

\begin{abstract}
Health workers in a surgical suite are exposed to various professional threats like biological, chemical, physical and psychosocial, all of which can lead to serious acute and long-term harmful outcomes. During the implementation of their duties surgical nurses/technicians are meeting various professional health problems. Surgical suite is a space where surgical team interacts among themselves with all the necessary technology. Surgical nurses/technicians, same as others are sensitive to stressful factors, they are exposed to specific work surroundings which require technical organization and experience, handling of precise instrumentation, mastery of complex techniques and a closed working environment, working with same people, working without interaction with a patient for a long time. Exactly because of complex work tasks and responsibility, surgical nurses/technicians are exposed to numerous stressful situations which are often too intense or long lasting, so because of that they are classified as a risk group for occurrence of burnout. All staff in a surgical suite must be familiar with the development of potential dangers, so they could avoid related injuries or exposures to other threats within the suite.
\end{abstract}

Key words: surgical nurses $\bullet$ surgery suite $\bullet$ occupational hazards $\bullet$ stress $\bullet$ burnout

Running head: Occupational Hazards and Risks and surgical ward

Autor za korespondenciju/Corresponding author: Blaženka Kozina, mag. med. techn., Operating center, Clinical Hospital Dubrava, Avenija Gojka Šuška 6, 10 000 Zagreb, Croatia • Tel: +385 1 $2902999 \cdot$ E-mail: kozinablazenka@gmail.com

\section{Uvod/Introduction}

U sestrinskoj profesiji, opasnosti i rizici različiti su i brojni. Neki su verificirani od nastanka struke, a odnedavno su priznati kao faktori rizika. Drugi zdravstveni problemi novijeg su datuma, a većina je nastala zbog ubrzanog razvoja novih tehnologija u zdravstvu.

Značajna ekonomska ulaganja u medicini dovela su do ubrzanog razvoja novih tehnologija, tehnika, vještina i resursa koji omogućuju brzo rješavanje zdravstvenih problema, a istovremeno smo suočeni s nedostatnim brojem zdravstvenih djelatnika, poteškoćama u stvaranju novih djelatnika. Stahl i sur. 2005. godine, u općoj bolnici u Massachusetssu [USA] proveli su istraživanje kojim su željeli procijeniti utje- caj uvođenja novih tehnologija u operacijskoj dvorani na stupanja zadovoljstva zaposlenika i incidenciju nastanka sindroma sagorijevanja [1]. Prema rezultatima istraživanja, uvođenje poboljšanih tehnologija predstavlja veći rizik za stres i sagorijevanje (engl. burnout), ali i mogućnosti pojedinca za prilagodbu na iste. Nadalje, autori ističu da poboljšane tehnologije čine posao lakšim i zanimljivijim što rezultira većom produktivnošću, efikasnijim radnim procesom i s većim stupnjem zadovoljstva u izvršavanju radnih zadataka.

Rezultati studije pokazuju da je poslije prvih šest mjeseci, kod djelatnika značajno smanjena emocionalna iscrplje- 
nost. U početku je veći stupanj emocionalne iscrpljenosti uočljiv među kirurzima, a manji je kod operacijskih sestara/ tehničara. Osjećaj osobnog postignuća među kirurzima veći je, nego li u operacijskih sestara/tehničara [1].

U sustavu zdravstva Republike Hrvatske krajem 2011. godine, bilo je stalno zaposleno 55.781 zdravstveni djelatnik i suradnik. U ukupnom broju zdravstvenih djelatnika, medicinske sestre čine 46\% [2]. Zdravstveni djelatnici mogu biti izloženi različitim rizicima u tijeku procesa rada u zdravstvenim ustanovama. Zakoni koji reguliraju navedeno područje jesu: Zakon o zaštiti na radu i Zakon o zdravstvenoj zaštiti [2].

\section{Opasnosti u operacijskoj dvorani}

Kirurzi, operacijske sestre/tehničari, anesteziolozi, anesteziološki tehničari svakodnevno su izloženi povećanim rizicima profesionalnih opasnosti poput bioloških, kemijskih, fizičkih, psihosocijalnih i sl.

Rezultati do danas publiciranih studija o opasnostima i faktorima rizika u operacijskoj dvorani, opisuju da operacijske sestre/tehničari imaju izrazito visok stupanj izloženosti faktorima rizika, kao što su: infektivni agensi, zračenje, buka, kiruški dim, gumene rukavice te anestetički plinovi [3].

\subsection{Biološke opasnosti}

Ubodne ozljede iglama i skalpelima, kao i kontaminacija kroz abrazije kože i rane kontamiranom krvlju, značajan su čimbenik rizika za djelatnike u operacijskoj dvorani [4]. Recentna literatura navodi da su sukladno normama, mjere opreza (smjernice o zaštititi zdravstvenih djelatnika kod izlaganja mikroorganizmima) niske u populaciji medicinskih sestara/tehničara [4]. Prije operacijskog zahvata, djelatnici u operacijskoj dvorani moraju biti upoznati s postojećim infekcijama bolesnika [npr. s HBV, HIV, sifilis i sl.]. Mjere zaštite od bioloških opasnosti moraju se primjenjivati prema relevantnim smjernicama.

\section{Lateks rukavice}

Operacijske sestre/tehničari u kontaktu su s krvlju, sekretima i izlučevinama bolesnika, te postoji značajan faktor rizika za nastanak neželjenih bolesti [HIV i hepatitis] $[5,6]$. Tijekom posljednjih 30 godina došlo je do veće uporabe medicinskih rukavica koje se upotrebljavaju prema opće prihvaćenim smjernicama i preporukama znanstveno stručnih institucija. Medicinske rukavice omogućuju veći stupanj sigurnosti zdravstvenim djelatnicima u svakodnevnom radu te istovremeno štite bolesnike od povećanog rizika za nastanak neželjene infekcije. Njihova uporaba kroz duže vrijeme može dovesti do oštećenja i ozljeda kože te nastanka iritativnog i alergijskog dermatitisa [6]. Nadražaj kože ili dermatoze, astma, nadraženost očiju, nosa i grla mogu biti uzrokovane alergijom na lateks. Prirodni izvor lateksa je mliječni sok od biljke Hevea braziliensis (kaučukovac), koji se industrijski obrađuje u različite proizvode od prirodne gume. Mnogi su mišljenja kako je problem u oblagajućem puderu u rukavicama. lako je puder prisutan, alergiju uzrokuju čestice latexa. Procjenjuje se kako alergiju na lateks ima $8-16 \%$ zdravstvenih djelat- nika, 24-64\% bolesnika sa spinom bifidom, 39\% bolesnika koji posjećuju zubare dok opća populacije ima nižu učestalost alergije na lateks, u rasponu od 1\% do 6,7\% [7]. U Republici Hrvatskoj juspostavljen je sustav za kontrolu infekcija povezanih sa zdravstvenom zaštitom zaposlenika u sustavu zdravstva. Opisuju se metode zaštite pri radu, metode u sprječavanju i suzbijanju bolničkih infekcija i povećanje stupnja sigurnosti svojih [2].

\subsection{Kemijske opasnosti}

Izlaganje anestetičkim plinovima, citotoksičnim lijekovima, sredstvima za čišćenje u operacijskoj dvorani može negativno utjecati na motoričku sposobnost, reflekse i budnost [5]. Dezinficijensi i sredstva za čišćenje mogu uzrokovati bolesti u djelatnika koji nisu zadovoljavajuće zaštićeni te mogu uzrokovati nastanak rinitisa, keratitisa, otežanog disanje, glavobolje, kontaktnog dermatitisa, astme, poremećaja pamćenja, nedostatka koncentracije i bolesti reproduktivnog sustava $[5,8,9]$. Djelatnici u operacijskoj dvorani, moraju biti upoznati s potencijalnim opasnostima.

\section{Kirurški dim}

Kirurzi i operacijske sestre/tehničari za vrijeme operacijskog zahvata izloženi su kirurškom dimu koji nastaje kao nusprodukt uređaja koji stvaraju toplinu. Sve što stvara toplinu [npr. električni kirurški nož, laserski snop svjetla, bušilice, pile] može proizvesti dim ili aerosol. Kirurški dim sastoji se od $95 \%$ vodene pare , a $5 \%$ sadrži potencijalno opasne čestice, uključujući kemikalije, krv i čestice tkiva, viruse i bakterije [10]. Tijekom posljednjih 30 godina, rezultati znanstvenih istraživanja pokazuju da kirurški dim ima toksične komponente kao i cigarete te predstavlja značajnu kemijsku i biološku opasnost za osoblje u operacijskoj dvorani [10,11,12]. Japanski znanstvenici otkrili su da potencijalna opasnost proizlazi iz udisanja kirurškog dima te da mutagenost od 1 grama kirurškog dima može otpustiti istu razinu mutagenih zagađivača kao tri do šest cigareta $[11,12,13]$.

Međunarodne znanstvene organizacije verificirale su smjernice i profesionalne standarde za poboljšanje stupnja zaštite medicinskih djelatnika u operacijskoj dvorani od kirurškog dima (ACORN, AORN,OSHA, NIOSH). Prema navedenim preporukama djelatnici u operacijskoj dvorani [14] moraju:

\section{- biti educirani o opasnostima od kirurškog dima;}

- koristiti odgovarajuću opremu i postupke kako bi se spriječilo izlaganje kirurškom dimu;

- koristiti uređaj za uklanjanje dima.

Danas nema specifičnih propisa koji se odnose na vrijeme izlaganja kirurškom dimu. Novije studije uočavaju da je motivacija, timski rad i edukacija djelatnika u operacijskoj dvorani o pravilnom korištenju najučinkovitija metoda zaštite.

\subsection{Fizičke opasnosti}

Tjelesne ozljede, posjekotine, ubodi, opekline i padovi neke su od najčešćih opasnosti u operacijskim dvoranama. Tijekom uporabe stare ili nepravilne opreme, može doći do strujnog udara ili požara što na kraju rezultira ozljedom. Operacijske lampe, dugoročni učinak njihovog jakog svje- 
tla, čini oči umornima. Ultraljubičaste zrake koriste se za dezinfekciju zraka, a kod operacijskih sestara/tehničara koji nisu dostatno zaštićeni može se razviti keratitis i konjuktivitis.

\section{Buka}

Buka u operacijskoj dvorani uzrokuje nezadovoljavajuću komunikaciju između djelatnika te može biti opasna za sigurnost bolesnika i uzrokovati profesionalni stres [15].

Rad u bučnom okruženju, štetno utječe na živčani, kardiovaskularni, endokrini i slušni sustav. Buku u operacijskoj dvorani proizvodi električna bušilica, pila, električni nož, aparat za sukciju, aparat za anesteziju, razgovor među djelatnicima. Duže izlaganje može uzrokovati glavobolje, nesanice, gubitak sluha i povišeni krvni tlak, a smanjen je stupanj intelektualne koncentracije [16].

Prema preporukama Svjetske zdravstvene organizacije [engl. WHO] razina buke u operacijskoj dvorani ne smije prelaziti $30 \mathrm{~dB}$ [17], a rezultati recentnih studija pokazuju da razgovor, instrumenti i buka aparata, redovito prelazi navedenu vrijednost $[15,16,17]$.

\section{Glazba}

Postoje razlike u mišljenju - treba li glazbu smatrati bukom? Ullmann i sur. (2008) tvrde da glazba može imati smirujući učinak na timski rad te je stoga razlikuje od drugih vrsta buke, koje smatra iritantnim [18]. U novijim studijama, anestetičari i medicinske sestre govore o manje poželjnom učinku glazbe. Primjerice jedan sustavni pregled pokazuje da glazba omogućuje veću brzinu i točnost za kirurga, ali smanjuje mogućnost suradnje i koordinaciju za ostale djelatnike kirurškog tima [19].

\section{Izloženost ionizirajućem zračenju}

Radiološke intervencije u zdravstvu su neizostavni dio liječenja bolesnika u dijagnostičke i terapijske svrhe. Količina ionizirajućeg zračenja i doza opterećenja na bolesnika i djelatnike operacijskog tima ovisi o složenosti i veličini kirurškog zahvata.

Sve osobe koje rade s izvorima ionizirajućeg zračenja moraju pohađati posebnu izobrazbu radi primjene metoda zaštite od ionizirajućeg zračenja. Metode zaštite moraju se primjenjivati i na bolesnicima u vrijeme izvođenja operacijskog zahvata.

\subsection{Psihosocijalne opasnosti}

Rad u operacijskoj dvorani sadrži značajnu brzinu kretnji te postojanje visokog stupnja rizika i povećanu incidenciju za nastanak mogućih komplikacija što za djelatnike u operacijskoj dvorani predstavlja dodatno opterećenje. Kirurški zahvati su s vremenom postali kompliciraniji i tehnički izazovniji što iziskuje od operacijskih sestara/tehničara dodatnu edukaciju, usvajanje novih znanja i vještine uz značajno smanjene mogućnosti pohađanja certificiranih programa zbog smanjenja „slobodnog vremena". U zdravstvenim djelatnostima u zemljama svijeta opisuje se opći nedostatak medicinskih sestara, što je vezano uz brojne organizacijske i psihološke probleme (stres, sagorijevanje) [20,21]. Stres na radnom mjestu u značajnom je obimu povećan posebice kod djelatnika u Europi, posebice u novim članicama EU [22]. Rezultati četvrte Europske ankete procjenjuju da je 40 milijuna ljudi u Europskoj uniji na radnom mjestu pod utjecajem stresa [23]. Stres na radnom mjestu pojavljuje se zbog prevelikih zahtjeva koje nalaže radno okruženje. U radu, postoji mnogo čimbenika koji uzrokuju preopterećenje. Neki primjeri radnih uvjeta koji dovode do psihosocijalnih rizika jesu [22]:

- pretjerano opterećenje;

- suprotstavljeni zahtjevi i nedostatak jasno definiranih uloga;

- nedostatak sudjelovanja u donošenju odluka koje utječu na radnika i nedostatak utjecaja na način obavljanja posla;

- loše upravljanje, organizacijske promjene, nesigurnost posla;

- neučinkovita komunikacija, nedostatak podrške od uprave ili kolega;

- psihološko i seksualno uznemiravanje, treća strana nasilja.

Niska razina odlučivanja i visoki zahtjevi, karakteristični za sestrinsku profesiju, mogu biti povezani s povećanim rizikom za nastanak koronarne bolesti i mentalnih poremećaja [24]. Prekomjerni stres uzrokuje nedosljednosti u ponašanju te često izostajanje s posla.

Medicinske sestre i tehničari, češće od liječnika, izloženi su stresorima na radu, i to zbog: male mogućnosti napredovanja i promaknuća, nedostatnog broja djelatnika, straha od izloženosti ionizirajućem zračenju, straha od izloženosti citostaticima, straha od mogućnosti zaraze u kontaktu s oboljelima, straha od mogućnosti ozljede oštrim predmetom [24]. U zdravstvenih djelatnika zaposlenih u bolničkim ustanovama najsnažnijim su stresorima prepoznati su oni iz 12. skupine financijskih i organizacijskih čimbenika, koji djeluju na radnu sposobnost u svim dobnim skupinama, a slijede opasnosti i štetnosti na poslu te smjenski rad. Studije provedene u populaciji medicinskih sestara/tehničara ukazuju na povezanost određenih bolesti sa stresom na radu, kao što su emocionalna iscrpljenost, fizička iscrpljenost i bol u donjem dijelu leđa $[22,24]$. Rezultati istraživanja o sukobu privatno - poslovno u odnosu na stres, sagorijevanje, opisuju da su medicinske sestre/tehničari često u sukobu s redovitim zadacima u svakodnevnom životu, što dovodi do stresa na poslu $[22,25]$. Pritisci prekovremenog rada i dugo radno vrijeme mogu stvoriti neravnotežu u privatno-poslovnom životu koja počinje utjecati na zdravlje zaposlenika. Traje li takva situacija dugo i akumulira se izvan sposobnosti samoregulacije, to može uzrokovati anksioznost, depresiju i napetost [25]. Osim psihičkih problema, zdravstveni djelatnici koji su izloženi dugotrajnom stresu, mogu razviti fizičke zdravstvene probleme kao što su kardiovaskularne bolesti ili koštano-mišićni problemi. Rezultati studije stresa kod medicinskih sestara u razvijenim zemljama ukazuju da kronični stres uzrokuje pojavu suicidalnih misli, pušenje, prekomjernu konzumaciju kave i unosa alkohola [26]. 
Potrebn je u budućnosti učiniti studije u svrhu poboljšanja razumijevanja nastanka stresa. Prekomjerni stres smanjuje sposobnost osobe da u kritičnim situacijama donese ispravnu odluku te uzrokuje nedosljednosti u ponašanju, kao i često izostajanje s posla. Operacijske sestre trebaju jačati svijest o samozaštiti, aktivno prilagoditi svoj stav, saznati više o svom radu te poboljšati svoje profesionalne sposobnosti. U privatnom životu trebaju organizirati svakodnevne aktivnosti, pokušati uskladiti profesionalnu zahtjeve s onim obiteljskim, imati razumijevanje i podršku članova obitelji. Na poslovima s povećanim rizicima potrebno je stalno pratiti zdravlje radnika s obzirom na veću opasnost od nastanka bolesti vezanih uz rad (uključujući i profesionalne bolesti) i ozljede na radu.

\section{Zaključak / Conclusion}

Operacijske sestre/tehničari izloženi su specifičnim opasnostima i štetnim čimbenicima što ukazuje na potrebu jačanja svijesti o samozaštiti. Obrazovanje i informiranje zdravstvenih djelatnika u sklopu provedbe mjera zaštite zdravlja osnovna je metoda prevencije. U budućnosti je potrebna izrada studija u svrhu poboljšanja razumijevanja nastanka stresa te politike koje će poboljšati ravnotežu privatnog i poslovnog života za medicinske sestre/tehničare. Organizacijska klima, pružanje socijalne podrške i povratne informacije kao potencijalna strategija za smanjenje stresa.

\section{Authors declare non-conflict of interest}

\section{Literatura / References}

[1] Stahl JE, Egan MT, Goldman JM, Tenney D, Wiklund RA, Sandberg WS, Gazelle S, Rattner DW. Introducing new technology into the operating room: measuring theimpact on job performance and satisfaction. Surgery. 2005;137(5):518-26

[2] Mustajbegović J, Skoko Poljak D. et al Nacrt-nacionalni program zaštite zdravlja i sigurnosti na radu osoba zaposlenih u djelatnosti zdravstvene zaštite za razdoblje 2013.-2020. Available at: http:// www.hzzzsr.hr/images/documents/zakonodavstvo/strategije/Nacionalni_program_zzsr_2015_2020.pdf. Accessed 30 th April 2017

[3] Van den Berg-Dijkmeijer ML, Frings-Dresen MH, Sluiter JK. Risks and health effects in operating room personnel. Work. 2011;39(3):331-44.

[4] Efstathiou G, Papastavrou E, Raftopoulos V, Merkouris A. Factors influencing nurses' compliance with Standard Precautions in order to avoid occupational exposure to microorganisms: A focus group study. BMC Nurs. 2011; 21;10:1

[5] Lin X, Hong S, Cai L, Progress in Protection of Nurses Working in Operating Room against Occupational Hazards, Chinese Journal of Nursing. 2015. Avalaible at: http://www.usp-pl.com/2015/08/25/progress-in-protection-of-nurses-working-in-operating-room-againstoccupational-hazards/. Accessed 30 th April 2017

[6] Sussman GL, Beezhold DH, Liss G. Latex allergy: historical perspective. Methods. 2002;27(1):3-9.

[7] AANA - American Association of Nurse Anesthetists, Latex Allergy Management, Guidelines by AANA Board of Directors. 2014. Available at: http://www.aana.com/resources2/professionalpractice/Pages/Latex-Allergy-Protocol.aspx. Accessed 30 th April 2017
[8] Hughes RG, editor. Patient Safety and Quality: An Evidence-Based Handbook for Nurses. Chapter 39 Personal Safety for Nurses 2008 Apr.

[9] Le Moual N, Varraso R, Zock JP, et al. Are operating room nurses at higher risk of severe persistent asthma?: The Nurses' Health Study. Journal of occupational and environmental medicine / American College of Occupational and Environmental Medicine. 2013;55(8):973-977.

[10] Gorman T, Dropkin J, Kamen J, Nimbalkar S, Zuckerman N, Lowe T, Szeinuk J, Milek D, Piligian G, Freund A. Controlling health hazards to hospital workers. New Solut. 2013;23 Suppl:1-167.

[11] Tomita $Y$, Mihashi S, Nagata K, Ueda S, Fujiki M, Hirano M, Hirohata T. Mutagenicity of smoke condensates induced by CO2-laser irradiation and electrocauterization. Mutat Res. 1981;89(2):145-9.

[12] Mowbray N, Ansell J, Warren N, Wall P, Torkington J. Is surgical smoke harmful to theater staff? a systematic review. Surg Endosc. 2013;27(9):3100-7.

[13] Hill DS, O'Neill JK, Powell RJ, Oliver DW. Surgical smoke - a health hazard in the operating theatre: a study to quantify exposure and a survey of the use of smoke extractor systems in UK plastic surgery units. J Plast Reconstr Aesthet Surg. 2012;65(7):911-6.

[14] Ulmer BC. The hazards of surgical smoke. AORN J. 2008 Apr;87(4):72134; quiz 735-8. Review. Avalaible at: http://www.op-produkte.de/ smoke.pdf. Accessed 30 th April 2017

[15] Hasfeldt D, Laerkner E, Birkelund R. Noise in the operating room - what do we know? A review of the literature. J Perianesth Nurs. 2010;25(6):380-6.

[16] Stringer B, Haines TA, Oudyk JD. Noisiness in operating theatres: nurses' perceptions and potential difficulty communicating. J Perioper Pract. 2008;18(9):384, 386-91

[17] Concha-Barrientos M, Campbell-Lendrum D, Steenland K. Occupational noise: assessing the burden of disease from work-related hearing impairment at national and local levels. Geneva; World Health Organization, 2004 Avalaible at: http://www.who.int/quantifying_ehimpacts/publications/en/ebd9.pdf.Accessed 30 th April 2017

[18] Ullmann Y, Fodor L, Schwarzberg I, Carmi N, Ullmann A, Ramon Y. The sounds of music in the operating room. Injury. 2008;39(5):592-7

[19] Weldon S, Korkiakangas T, Bezemer J, Kneebone R et al., Music and communication in the operating theatre, Journal of Advanced Nursing, ISSN: 1365-2648

[20] Ilhan MN, Durukan E, Taner E, Maral I, Bumin MA. Burnout and its correlates among nursing staff: questionnaire survey. J Adv Nurs. 2008;61(1):100-6. Epub 2007 Nov 22. PubMed

[21] Wu S, Zhu W, Wang Z, Wang M, Lan Y. Relationship between burnout and occupational stress among nurses in China. J Adv Nurs. 2007;59(3):233-9. Epub 2007 Jun 21. PubMed

[22] EU-OSHA - European Agency for Safety and Health at Work, 'OSH in figures: Stress at work - facts and figures', Office for Official Publications of the European Communities, Luxembourg, 2009. Available at: http://osha.europa.eu/en/publications/reports/TE-81-08-478-EN-C_ OSH_in_figures_stress_at_work. Accessed 30 ${ }^{\text {th }}$ April 2017

[23] Eurofound - European Foundation for Working and Living Conditions, The Fourth Working Conditions Survey. Office for Official Publications of the European Communities, Dublin, 2007. Available at: http://www.eurofound.europa.eu/pubdocs/2006/98/en/2/ef0698en. pdf. Accessed 30th April 2017

[24] Kneževic B, Golubić R, Milošević M, Matec L, Mustajbegović J. Zdravstveni djelatnici u bolnicama i stres na radu: istraživanje u Zagrebu. Sigurnost 2009;51(2): 85-92.

[25] Patient Safety and Quality: An Evidence-Based Handbook for Nurses. Chapter 26 Work Stress and Burnout Among Nurses: Role of the Work Environment and Working Conditions 2008 Apr.

[26] Kane PP. Stress causing psychosomatic illness among nurses. Indian Journal of Occupational and Environmental Medicine. 2009;13(1):2832. 